\title{
Snapshots of Baccalaureate Health Humanities Programs
}

\author{
Erin Gentry Lamb $^{1} \cdot$ Sarah Berry ${ }^{2}$
}

Published online: 3 July 2017

(C) Springer Science+Business Media, LLC 2017

We invited baccalaureate educators to submit key facts and brief descriptions of their health humanities programs. Below are snapshots of thirty-five different programs across thirty-three different institutions. Taken together, these snapshots offer a glimpse of the diversity of the programs' curricular structure and institutional location; they also show some interesting commonalities in terms of educational goals and - with some exceptions - a predominant orientation toward pre-health professions students. We have included among these snapshots the only postbaccalaureate program of which we are currently aware that incorporates health humanities into its curriculum: Eastern Mennonite University. As health humanists working at the baccalaureate level continue to define the contours of our field, it will be useful to collect a more complete survey of program structure (including introductory courses, if available, and the content of those courses), program housing, and stated educational goals. A more complete list of baccalaureate health humanities programs is available in a report by Berry, Lamb and Jones available online at http://www.hiram.edu/centers-of-distinction/litmed/baccalaureate-health-humanities.

Appalachian State University (Medical Humanities Minor)

Baylor University (Medical Humanities Major, Minor)

Benedictine University (Medical Humanities Major)

Boston College (Medical Humanities, Health, and Culture Minor)

Drexel University (Medical Humanities Certificate)

DePaul University (Health Sciences Major, Minor)

DePaul University (Bioethics \& Society Minor)

Eastern Mennonite University (Masters of Arts in Biomedicine, Post-Bacc MA)

Florida Atlantic University - Wilkes Honors College (Honors Medical Humanities Concentration)

Erin Gentry Lamb

lambeg@hiram.edu

Sarah Berry

sarahberryphd@gmail.com

1 Biomedical Humanities, Hiram College, Hiram, OH 44234, USA

2 Humanities, Centre College, Danville, KY 40422, USA 
Hiram College (Biomedical Humanities Major, Minor)

Hofstra University (Medicine, Culture and Society Minor)

Indiana University - Purdue University Indianapolis (Medical Humanities and Health Studies Major, Minor)

Lehigh University (Health, Medicine and Society Minor)

Misericordia University (Medical and Health Humanities Major, Minor)

Ohio Northern University (Medical Humanities Minor)

Oregon State University (Medical Humanities Certificate)

Saint Louis University (Medical Humanities Interdisciplinary Minor)

Schreiner University (Medical Humanities Minor)

The Ohio State University (Medical Humanities Minor)

The Pennsylvania State University (Bioethics and Medical Humanities Minor)

University of Alabama (Philosophy and Medicine Major, Minor)

University of Colorado Denver (Health Humanities Minor)

University of Delaware (Medical Humanities Minor)

University of Massachusetts (Science, Medicine, and Society Past \& Present Minor)

University of Nebraska - Lincoln (Humanities in Medicine Minor)

University of Oklahoma (Medical Humanities Minor + BA-MD)

University of Pittsburgh (Conceptual Foundations of Medicine Certificate)

University of Pittsburgh (Medical Humanities Certificate)

University of Texas-San Antonio (Medical Humanities Major)

University of Texas-Dallas (Medical and Scientific Humanities [MaSH] Minor)

University of Washington (Bioethics Minor)

Virginia Commonwealth University (Medical Humanities Minor)

Washington University (Medical Humanities Minor)

West Virginia University (Medical Humanities and Health Studies Minor)

Western Michigan University (Medical Humanities Minor)

Institution: Appalachian State University

Program: Medical Humanities

Type: Minor

Location: The Honors College

Established: 2009

Contact: Celeste Crowe

Director, Health Professions Advising

crowect@appstate.edu

(828) 262-8970

Program The Minor in Medical Humanities is designed for the health care pre-

Description: professional who wants to have a richer and broader program of study than just the required major or courses. By pursuing this Minor, students will explore questions in the Humanities and Social Sciences that have a direct bearing on health care today. Courses such as Medical Ethics and Health Law, for example, will take the students into current issues of health care practice through the prism of ethical and legal concerns. Courses like Chinese Medicine and Our Primate Heritage will extend the student's 
thinking into the history of health care and the growing field of evolutionary medicine. While this Minor and most of these courses are not required for medical school or any other health care graduate program, students will find that the Minor will strengthen their application for those programs both for what it says on their transcript and for what it does to their thinking, writing, and speaking. This Minor is for those students who want a bit more than the standard preparation for their health care field of choice and for students who are already in Honors or who want to be able to take some Honors courses even if they are not. The Minor is administered by The Honors College, but application is open to all students in the University with a $3.3 \mathrm{GPA}$, and all students accepted in the Minor may sign up for any Honors courses in the Minor.

$\begin{array}{ll}\text { Institution: } & \text { Baylor University } \\ \text { Program: } & \text { Medical Humanities } \\ \text { Type: } & \text { Major, Minor } \\ \text { Location: } & \text { College of Arts and Sciences } \\ \text { Established: } & 2002 \\ \text { Contact: } & \text { Lauren Barron } \\ & \text { Clinical Professor and Director, Medical Humanities Program } \\ & \text { lauren_barron@ baylor.edu } \\ & \text { (254) } 710-2066\end{array}$

Program The mission of the Medical Humanities Program at Baylor University is to Description: educate men and women for worldwide service and leadership in healthcare by integrating academic excellence and Christian commitment. We seek to provide a truly transformational education for undergraduate students who aspire to work in and around the healthcare professions by equipping them with a rich exposure to the humanities in addition to an outstanding foundation in the sciences - all under the guidance of faculty who are committed to compelling scholarship and dedicated to service. It is a truly interdisciplinary program, consisting of courses taught by faculty from many departments, including English, religion, philosophy, history, sociology, and psychology. We feature innovative courses taught by clinical faculty that focus on the importance of the relationship between patient and practitioner, the role of spirituality in healthcare, and the changing nature of healthcare in the twentyfirst century. First established in 2002, we have enjoyed tremendous growth and currently have well over 200 students enrolled in our program. In addition to our course offerings, the Medical Humanities Program sponsors opportunities for clinical experiences, research and service learning in close connection with our local medical community. Housed in the College of Arts and Sciences, we work closely with the Office of PreHealth Studies, the Honors College and partners throughout the university to extend our programming to all students with an interest in healthcare, and not just to students subscribed to our major or minor. 
Institution: Benedictine University

Program: Medical Humanities

Type: Major

Location: College of Liberal Arts

Established: 2009

Contact: Elizabeth Kubek

Professor of Literature; Director, Medical Humanities

ekubek@ben.edu

(630) 829-6257

Program The Medical Humanities major at Benedictine University is designed to prepare

Description: students for medical school, graduate work in interdisciplinary science/ humanities programs, global scientific research, patient advocacy, or other careers that require advanced work at the intersections of the life sciences and the humanities. As of 2016 the major has been revised to include a separate Pre-Medical concentration which reflects changes to the MCAT. The objectives of the Medical Humanities program are: advance students' awareness of the interconnectedness and larger relevance of the academic disciplines; expose students to current ideas and practices that "humanize" the medical sciences, and vice versa; encourage students to make productive connections between their practical knowledge, daily activities, ethical values, and relations with others and the environment; foster collaboration between students, faculty, and health professionals; educate accomplished future professionals who are also engaged, responsible global citizens; promote the creation of a medical and research community that includes regard for patients and practitioners as whole persons; and provide future professionals with critical and ethical tools that will enable them to transform their profession and remain informed and engaged throughout their lives. Program-Level Student Learning Outcomes (SLOs) require students to: Apply and integrate knowledge from the sciences, social sciences, arts, and humanities to the study of scientific practice in its global and social contexts; Explain and analyze the personal and psychological aspects of medical fields, including the experiences of patients and practitioners; and Design a course of study within the Arts, Humanities, and Social Sciences that informs an individual research agenda.

\author{
Institution: Boston College \\ Program: Medical Humanities, Health, and Culture \\ Type: Minor \\ Location: Morrissey College of Arts and Sciences \\ Established: 2013 \\ Contact: Amy Boesky \\ Program Director \\ amy.boesky@bc.edu
}

Program The Medical Humanities, Health, and Culture Minor at Boston College is an

Description: eighteen credit interdisciplinary minor engaged in the humanistic and cultural 
study of illness, health, health care, and the body. Students choose courses from a range of departments from the social sciences and the humanities to the natural sciences. Over twenty affiliated faculty in eleven different departments provide instruction and support. Throughout, the minor draws from Boston College's commitment to social justice, ethics, and care for the whole person. Started in the fall of 2013, the minor has grown quickly with 150 students from a variety of majors enrolled in the program. Current minors are planning careers in medicine, health care policy or law, psychology, public/global health, social work, patient advocacy, or health journalism. Other minors, undecided about career path, are interested in learning more about bioethics, the history of health practices, or the narrative contexts for current (and at times competing) ideas about illness and the body. The minor is also home to student-run initiatives including an interdisciplinary journal and a recent regional conference.

$\begin{array}{ll}\text { Institution: } & \text { Drexel University } \\ \text { Program: } & \text { Medical Humanities } \\ \text { Type: } & \text { Certificate } \\ \text { Location: } & \text { Department of English and Philosophy, } \\ & \text { College of Arts and Sciences }\end{array}$

Established: 2006

Contact: $\quad$ Stacey Ake and Emilie S. Passow

Co-Directors, Certificate Program in Medical Humanities

Ake: sea29@drexel.edu, (215) 895-6819

Passow: snde333@gmail.com, (610) 664-0241

Program Our Certificate Program in Medical Humanities is designed especially for Description: students majoring in any of the biological sciences, biomedical engineering, nursing, public health, and psychology with the aim of promoting dialogue and mutual appreciation for various approaches to health related issues. Since we are all bound to be either or both patients and caregivers in our lives, majors in other humanities subjects are welcome. The program is also open for an Honors option. The wide range of applicable courses fosters an interdisciplinary context for investigating the many challenges within medicine and caregiving. This format, in turn, encourages students to explore illness, disability, dying and healing as experiences, not conditions, and to evaluate limitations of an exclusively scientific perspective on medical practice and research. After taking these courses students will be able to 1 . Recognize the multiple factors ((i.e.. economic, technological, cultural, ethical and institutional and political) that complicate the role of the physician and the patient in contemporary American society. 2. Understand illness, disability and the art and science of medical practice and care-giving as multi-layered experiences that can affect the patient's and the medical provider's sense of identity, relationship to others, and the sense of purpose and responsibility. 3. Clearly and cohesively analyze how intentional use of language, narrative patterns, 
and literary strategies in course texts, (i.e. fiction, non-fiction, poetry, film, and scientific research) contribute to goals 1 and 2. One of the mantras of the program is that healing is possible even when there is no cure.

$\begin{array}{ll}\text { Institution: } & \text { DePaul University } \\ \text { Program: } & \text { Health Sciences } \\ \text { Type: } & \text { Major, Minor } \\ \text { Location: } & \text { Department of Health Sciences } \\ \text { Established: } & 2012 \\ \text { Contact: } & \text { Craig Klugman } \\ & \text { Professor of Health Studies } \\ & \text { cklugman@ depaul.edu } \\ & \text { (773) 325-4876 }\end{array}$

Program The mission of DePaul University's Department of Health Sciences is to Description: educate and train students who will collaboratively address human health from interdisciplinary natural and social scientific perspectives in order to promote health and to improve the lives of individuals and communities. The goal is to give students a background to help them understand a 360-degree perspective of health. Students complete 68 credits (35\% of all courses) in the liberal studies program in addition to their major requirement of 88 credits (45\% of all courses). We have a major core set of integrated, interdisciplinary classes and then students choose either the BioScience or the Public Health Studies concentration. The former places more emphasis on biology, chemistry, and physics while the latter emphasizes social science. All students take courses in introduction to health, critical reading, public health, general biology, statistics as well as natural and social science. Beyond a required bioethics course, we offer several medical humanities elective courses including Medical Humanities, Bioethics in Society, Death \& Dying, Medical Anthropology, Health Communication, Health Disparities, and Health Leadership.

Institution: DePaul University

Program: Bioethics \& Society

Type: Minor

Location: Departments of Health Sciences \& Philosophy (jointly administered)

Established: 2016

Contact: Craig Klugman

Professor of Health Studies

cklugman@depaul.edu

(773) 325-4876

Program The Minor in Bioethics and Society offers students an interdisciplinary ap-

Description: proach to the various moral, social, political, and conceptual issues that arise at the ever changing intersection of the life sciences, health, and society. All students take an introduction to bioethics course (either through a philosophical, religious or clinical lens). Students choose among related courses in 
philosophy, religion, health and sociology (one course in each area). All students then complete Bioethics In Society, a capstone course that critically examines the function and role of bioethics.

$\begin{array}{ll}\text { Institution: } & \text { Eastern Mennonite University } \\ \text { Program: } & \text { Master of Arts in Biomedicine } \\ \text { Type: } & \text { Masters of Arts (Post-Bacc) } \\ \text { Location: } & \text { School of Graduate and Professional Studies } \\ \text { Established: } & 2012 \\ \text { Contact: } & \text { Julia Halterman } \\ & \text { Assistant Professor of Biology } \\ & \text { julia.halterman@emu.edu } \\ & \text { (540) 432-4407 }\end{array}$

Program As the demand for post-baccalaureate biomedical education increases, our Description: nation has experienced a rapid rise in the number of certificate and masters programs now available to students. Coupled with this growth, professional benchmarks must be identified to frame standards and best practices for this emerging field. The Masters of Arts in Biomedicine post-baccalaureate program at Eastern Mennonite University has a model that offers a holistic, transdisciplinary, and global approach to biomedical education. This transdisciplinary model of a masters biomedicine program provides students with a strong foundational understanding of the natural sciences but also uniquely educates students on how the humanities should inform their worldview. Our students are encouraged to expand their view of healthcare and healing by studying the interrelationship between natural science, sociology, psychology, religion, philosophy, and the visual arts. We additionally believe that spirituality is a vital component of health, and we motivate our students to explore the role of their faith traditions in their professional lives and in the lives of their future patients. The mission of our masters program is for graduates to 1) exhibit scientific and technical excellence in preparation for entering the medical field, 2) embody their faith through spiritually and ethically anchored practices of holistic health, and 3) display globally-informed and interdisciplinary approaches to medical leadership. Students learn and practice these skills through a unique transdisciplinary biomedicine curriculum and crosscultural travel to learn and serve in a global healthcare environment.

Institution: Florida Atlantic University - Wilkes Honors College

Program: Honors Medical Humanities

Type: Concentration

Location: Harriet L. Wilkes Honors College of FAU

Established: 2013

Contact: Dorotha Lemeh

Associate Professor of Visual Art

dlemeh@fau.edu

(561) 799-8019 
Program Healthcare professionals (physicians, nurses, psychotherapists, occupa-

Description: tional therapists, biomedical engineers, language pathologists, etc.) must be able to relate to patients on a human level - morally, by being sympathetic or empathetic; interpersonally, by being able to elicit appropriate responses and communicate effectively; and creatively, in their ability to analyze patients' symptoms and conditions to effectively diagnose and recommend treatment. The Wilkes Honors College's undergraduate concentration in Medical Humanities is predicated on the notion that these skills should be developed and honed throughout a students' academic career prior to entering the health care profession. As an undergraduate, interdisciplinary program, the Medical Humanities concentration is founded on the notion that a pre-med or healthcare curriculum can be enhanced by integrating into those curriculum elements of the arts, humanities, and sciences that provide valuable insight into human nature, the human condition, the nature of understanding, and creative discovery. For this reason, the Honors College interprets the Medical Humanities broadly to include, and indeed require, multiple disciplines of study. Such a broad-based education assists students in becoming more observant and reflective, and trains them in multiple methodologies, all of which help to promote integrity, ethics, and humane, holistic approaches to public health and healthcare. The Medical Humanities concentration provides students a pathway to medical school and the healthcare profession. This undergraduate concentration supports the analytical approaches based on reason and method used in the sciences and encourages creative problem solving methods, intuitive thinking, and other methods of learning and discovery which facilitate understanding and communication.

$\begin{array}{ll}\text { Institution: } & \text { Hiram College } \\ \text { Program: } & \text { Biomedical Humanities } \\ \text { Type: } & \text { Major, Minor } \\ \text { Location: } & \text { Department of Biomedical Humanities } \\ \text { Established: } & 1993 \\ \text { Contact: } & \text { Erin Lamb } \\ & \text { Associate Professor of Biomedical Humanities; } \\ & \text { Director, Center for Literature and Medicine } \\ & \text { lambeg@hiram.edu } \\ & \text { (330) 569-6139 }\end{array}$

Program The biomedical humanities major at Hiram College is an innovative and Description: interdisciplinary area of study designed to prepare students for successful careers in a range of health care fields. The major couples an intensive science core - one geared towards the requirements for health professions schools with a curriculum that integrates courses in medical humanities and communication. With an emphasis on preparing students for careers in the medical 
field, all biomedical humanities majors are required to participate in four internships: one in biomedical research, one in clinical shadowing and two service learning projects. The course of study, combined with internship requirements, enables students to develop a balanced approach to health care. Hiram's students of biomedical humanities leave our program with the deep scientific knowledge and broad understanding of the humanities essential for success in graduate programs and the medical field.

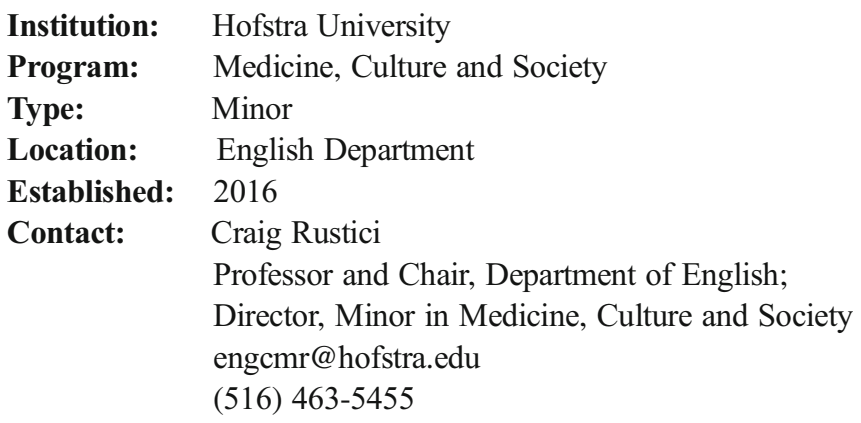

Program Students use a course in medical anthropology, bioethics, sociology of health or

Description: religion and medicine as an introduction to the minor. Students then complete four electives (at least one in the humanities and at least one in the social sciences). Students conclude with a capstone on medical humanities. Students thus investigate questions of health, healing, and disease from multiple disciplinary perspectives and integrate their insights in an interdisciplinary capstone.

Institution: Indiana University - Purdue University Indianapolis

Program: Medical Humanities and Health Studies

Type: Major, Minor

Location: School of Liberal Arts

Established: 1999

Contact: Emily Beckman

Director, Assistant Professor, Medical Humanities and Health Studies Program embeckma@iupui.edu

(317) $274-4755$

Program The Medical Humanities and Health Studies (MHHS) Program at IUPUI offers

Description: an interdisciplinary curriculum within the School of Liberal Arts to prepare undergraduates to understand the broader role and determinants of health and medicine in today's world. Students benefit from the wealth of humanities and social science faculty in Liberal Arts and other schools at the IUPUI campus (Medicine, Nursing, Public Health, Law) who have strong teaching and research interests in the area of health care. The MHHS Program provides a unique opportunity for students to explore the concepts of health and illness from an interdisciplinary and multidisciplinary perspective. The BA degree 
combines interdisciplinary courses, as well as electives in humanities and social science disciplines, culminating in a senior year capstone interdisciplinary research seminar. The undergraduate minor ( 15 credit hours) requires 6 hours of interdisciplinary course work and 9 hours of electives. Many students prepare for further study in graduate or professional school, and others gain employment upon graduation by planning their degree program curricula to take advantage of electives and distribution requirements to obtain specific skills that will make them employable in a variety of entry-level positions. Graduates have pursued numerous career paths, including but not limited to social/economic research, medicine, allied health professions, dentistry, health law, medical social work, nursing, public health, and public policy studies. Our graduates have gone on to pursue advanced degrees in pharmacy, medicine, occupational therapy, narrative medicine and other health professions, as well as law and graduate school programs.

$\begin{array}{ll}\text { Institution: } & \text { Lehigh University } \\ \text { Program: } & \text { Health, Medicine and Society } \\ \text { Type: } & \text { Minor } \\ \text { Location: } & \text { College of Arts and Sciences } \\ \text { Established: } & 2008 \\ \text { Contact: } & \text { Kelly Austin } \\ & \text { Director, Health, Medicine and Society Program } \\ & \text { kellyaustin@ lehigh.edu }\end{array}$

Program The Health, Medicine and Society program offers a minor composed of courses Description: with social science and humanities perspectives on health and illness. The HMS Program prepares students to meet the increasingly complex health needs of the growing global population, including emphasis on domestic and international health topics such as healthcare, aging, and infectious disease. The HMS program cultivates a broad understanding of the effects of health, illness, and medical care on individuals, families, communities, and societies. An interdisciplinary group of faculty created HMS to serve students who wish to contribute to any of the wide variety of health care professions, including administration, care-giving, policy, and research in multiple fields. In addition to a range of courses, the program hosts speakers and events designed to deepen the university and local communities' understanding of U.S. and global health issues.

\author{
Institution: Misericordia University \\ Program: Medical and Health Humanities \\ Type: Major, Minor \\ Location: College of Arts and Sciences \\ Established: 2016 \\ Contact: Amanda Caleb \\ Associate Professor of English and Director, \\ Medical and Health Humanities Program \\ acaleb@misericordia.edu
}

(570) 674-8113 
Program Misericordia's BA in Medical and Health Humanities integrates

Description: intellectually-rigorous courses with fieldwork experience that will comprehensively prepare students for future employment and a life of serving others with respect, compassion, and empathy. As a collaboration of academic disciplines in the Humanities, Health Sciences, and Sciences, the program offers a broad educational experience that challenges students to view healthcare through the lens of cultural, familial, philosophical, spiritual, mental, and social conditions. The program integrates courses from traditional academic departments and foundational and advanced coursework in Medical and Health Humanities with fieldwork experience to encourage a holistic perspective of health and the human. Courses such as Literature and Medicine, History of Medicine and Health, and Philosophy of Medicine engage critically in multi-disciplinary approaches to health and illness. In Medical Narrative, students investigate the relationship between health, healing, and social justice-concepts that are explored in the interdisciplinary introductory and capstone courses. In combining a course on Medical Ethics with a fieldwork experience, students make connections between the theoretical and the practical, moving beyond the biomedical model to understand medicine within a human and humane context. In the fieldwork course, students gain hands-on experience by choosing either an internship with a medical/health organization or an observational rotation at a medical/health facility. For the internship option, students apply academic knowledge to work experience; for the observation rotation, students attend clinical meetings and participate in on-site observations. Such experiences strengthen student portfolios when pursuing careers after graduation.

$\begin{array}{ll}\text { Institution: } & \text { Ohio Northern University } \\ \text { Program: } & \text { Medical Humanities } \\ \text { Type: } & \text { Minor } \\ \text { Location: } & \text { Getty College of Arts and Sciences } \\ \text { Established: } & 2015 \\ \text { Contact: } & \text { Douglas Dowland } \\ & \text { Assistant Professor of English, } \\ & \text { Chair of Medical Humanities Committee } \\ & \text { d-dowland@onu.edu }\end{array}$

(419) $772-2422$

Program The minor in Medical Humanities is one of several new interdiscplinary Description: minors at Ohio Northern. It is steered by a committee of five faculty from at least three different departments within the College of Arts and Sciences. With a core in the humanities (literature and philosophy) and electives in communications and the social sciences, the minor is designed as an accompaniment to ONU's strengths in pharmacy, 
nursing, and pre-medicine. Many courses offered in the minor also substitute for general education requirements. Of particular note is the integrative portfolio project, a capstone in which students synthesize coursework throughout the minor into a cumulative paper or project that can be presented at undergraduate research conferences locally or nationally. In these ways, the minor emphasizes an integration between the humanities and the professions and facilitates interdisciplinary conversation for both faculty and students.

$\begin{array}{ll}\text { Institution: } & \text { Oregon State University } \\ \text { Program: } & \text { Medical Humanities } \\ \text { Type: } & \text { Certificate } \\ \text { Location: } & \text { School of History, Philosophy, and Religion; } \\ & \text { School of Writing, Literature, and Film }\end{array}$

Established: 2010

Contact: Courtney Campbell

Hunder Professor in Religion and Culture ccampbell@oregonstate.edu

(541) 737-6196

Program

Description:
The undergraduate Certificate (i.e. interdisciplinary minor) in Medical Humanities offers OSU students a multi-disciplinary integrated program to study health, medicine and the healing professions. The certificate relies on key courses in medical anthropology, literature and medicine, medical history, and biomedical ethics for its core content foundations; courses from an additional nine different disciplines - biology, ethnic studies, exercise science, philosophy, political science, psychology, public health, religious studies, sociology, and women studies - fulfill complementary elective courses. Students also participate in a special colloquium on "the art of healing" that emphasizes skills in professional identity, reflective writing, cultural competency, engagement with care providers, and diversity as ways to complement to the scientific competencies of the healing professions. The certificate prepares students to reflect critically on medical knowledge and discourse; confront moral, psychological, and ethical dilemmas. Create new representations of the medical experience; and, empathize with the sufferings of others. Through affiliation with the Hundere Endowment in Religion and Culture, certificate students have opportunities for conversations and classes with prominent educators in the medical humanities and attend workshops with leading physician-writers. Students may also participate in opportunities for collaborative research with faculty members, which culminates in presentations at student or professional conferences and publications in leading journals. Students and faculty also partner in outreach programs and community engagement efforts with local providers, medical students and residents, and health care organizations. 


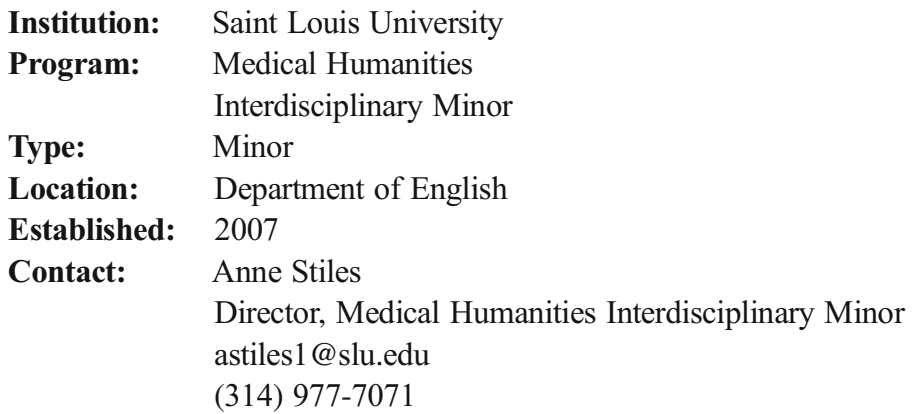

Program Since fall 2007, Saint Louis University (SLU) has offered an Interdisciplinary Description: Minor in Medical Humanities. This program is housed in the English Department and involves 21 units of graded coursework in literature, history, philosophy, theology, health care ethics, and allied disciplines. Students may also complete an optional 3-credit internship in a health-care setting. In their senior year, students write a 18-20 page capstone project as the culmination of their experience in the Minor. They then have the opportunity to present this capstone paper at SLU's annual Senior Legacy Symposium each spring. While the program is open to all SLU undergraduates, it is designed to help future health-care practitioners reflect upon the ethical and humanistic dimensions of medical care before embarking on a rigorous graduate education in their chosen field. In their medical humanities coursework, students are encouraged to contrast doctor, patient, and caregiver experiences; consider how diagnoses are culturally and historically constructed; cultivate interpretive and narrative competence; and to understand the crucial role such competence plays in health care delivery. As a result of this training, students develop writing and public speaking skills valued by medical and professional schools. They also better understand the many challenges facing modern health care professionals. Our graduates regularly go on to careers in medicine, physical therapy, social work, and related fields. For more information, see our website: http://www.slu.edu/medical-humanities-minor, which includes a link to the undergraduate advising form: http://www.slu.edu/medical-humanitiesminor/advising-form, or contact the program Director, Professor Anne Stiles, at astiles1@slu.edu.

$\begin{array}{ll}\text { Institution: } & \text { Schreiner University } \\ \text { Program: } & \text { Medical Humanities } \\ \text { Type: } & \text { Minor } \\ \text { Location: } & \text { Various departments (Interdisciplinary) } \\ \text { Established: } & 2015 \\ \text { Contact: } & \text { Krisann Muskievicz } \\ & \text { Coordinator, Minor in Medical Humanities; } \\ & \text { Assistant Professor, English } \\ & \text { kemuskievicz@ schreiner.edu } \\ & (830) 895-7105\end{array}$


Program A minor in Medical Humanities at Schreiner University challenges stuDescription: dents to investigate the human art of health care within the context of Liberal Arts education. Choices within the minor include courses in English, Philosophy, Psychology, Art, and Interdisciplinary Studies. The minor enhances degree plans in numerous majors by offering substantive study in theory. The inquiry offered by the minor will complement any health-careers degree plan and will add focused investigation of topics in the art of health care. The messiness of being human calls on compassionate providers to engage in studies of vulnerability, interconnectedness, expectation, ambiguity, and care beyond the limits of cure. Student objectives for the Minor in Medical Humanities are to: -become fluent in the terminology and history of the discipline of the Medical Humanities; reflect critically on seminal readings in the Medical Humanities; -reflect critically on representations of health, illness, and care; -develop an understanding of ethical theories and principles required for the analysis of ethical dilemmas encountered in contemporary health care practice; identify dilemmas common in health care as they are represented in written and visual texts; -develop an understanding of the intellectual influences that inspired Renaissance Humanism and, subsequently, the Medical Humanities; -articulate connections between Renaissance Humanism and the context of contemporary scientific discovery; -articulate ethical complexities surrounding contexts of care, competing needs/limited resources, professional duties, and moral stance; -articulate personal reflections of meaningful work, including topics regarding a tolerance for ambiguity, personal ethics (arête, phronesis), recognition of bias, and professional codes of ethics.

$\begin{array}{ll}\text { Institution: } & \text { The Ohio State University } \\ \text { Program: } & \text { Medical Humanities } \\ \text { Type: } & \text { Minor } \\ \text { Location: } & \text { Department of English }\end{array}$

Established: 2015

Contact: Pablo Tanguay

Undergraduate Program Manager, Dept. of English tanguay.1@osu.edu

(614) 292-6065

Program This 15-credit hour interdisciplinary undergraduate minor in Medical Description: Humanities instructs students about the social and cultural contexts of health, illness, and medical care. The minor offers critical perspectives on medicine not only as a body of technical and scientific knowledge, but also as a cultural process. It will benefit students seeking to do graduate work in fields related to the health professions, those seeking employment in the health professions immediately after graduation, and those seeking to expand their knowledge of issues in health care as part of their undergraduate education. 
Institution: The Pennsylvania State University

Program: Bioethics and Medical Humanities

Type: Minor

Location: Bioethics Program

Established: 2006

Contact: Jonathan Marks

Director, Bioethics Program

marks@psu.edu

(814) 865-5938

Program At Penn State, bioethics does not just mean clinical ethics. We also work

Description: on research ethics, health law and policy, global health and environmental ethics. And we ask big questions. How does industry funding affect pharmaceutical research and leading studies in food science? Can we hold a meaningful discussion about physician-assisted suicide in a nation that does not have universal access to health care? Do we have a right to health care, and what are the implications of such a right for health care rationing? Our program was developed as an initiative of the Rock Ethics Institute to bring together faculty from several other colleges including the College of Medicine, the College of Health and Human Development (home of the School of Nursing), the Dickinson School of Law, the College of Engineering, the Smeal College of Business, the Eberly College of Science and the College of Agricultural Sciences. Faculty associated with the program have affiliations with and/or collaborate with several interdisciplinary consortia at Penn State, including the Huck Institutes of the Life Sciences, the Institutes of Energy and the Environment and the Children, Youth and Family Consortium. By drawing on a variety of faculty with a wide range of experiences and expertise at University Park and other campuses, the program offers an innovative interdisciplinary curriculum. We currently offer an undergraduate minor in bioethics and medical humanities and the first graduate degree of its kind in the United States, a dual-title Ph.D. program in bioethics. We also hold conferences and seminars.

Institution: University of Alabama

Program: Philosophy and Medicine

Type: $\quad$ Major, Minor

Location: Department of Philosophy

Established: 2014

Contact: Richard Richards

Professor and Chair, Department of Philosophy

rrichard@ua.edu

(205) 348-5942

Program The University of Alabama department of Philosophy offers Philosophy

Description: and Medicine major and minor specializations, based on a series of 
courses introducing topics, issues, questions and problems associated with the practice of medicine: concepts of health and disease, evidence based medicine, medical reasoning, the status of mental diseases, evolutionary medicine, public policy, and medical ethics. While these concentrations are designed for those who are planning a career in the medical fields, they are open to any student with an interest in medicine. The Philosophy and Medicine Major and Minor both require courses in the Philosophy of Medicine, and Medical Ethics. The Philosophy and Medicine Major requires completion of 30 hours total in philosophy classes, including PHL 195: Introduction to Deductive Logic, PHL 211: Ancient Philosophy, and PHL 212: Early Modern Philosophy. The Philosophy and Medicine Minor requires the completion of 18 hours total from a list of relevant philosophy classes.

Institution: University of Colorado Denver

Program: Health Humanities

Type: Minor

Location: College of Liberal Arts and Sciences

Established: 2012

Contact: Therese Jones

Director, Arts and Humanities in Healthcare Program therese.jones@ucdenver.edu

Program The minor in Health Humanities highlights humanities and related social Description: science approaches to medicine and health and has special benefit for premed students and students pursuing health careers in general as well as wide appeal for liberal arts students who are interested in scientific and medical issues from a humanistic perspective. Humanistic studies of health provide an excellent addition to science-based curricula and also serve as a valuable stand-alone program, addressing current issues and interests. Faculty across the College play an integral role in inculcating the values of a liberal arts tradition in healthcare contexts, and the minor builds on the existing strengths of the Anschutz Medical Campus and bolsters existing BA/MD and Public Health programs. The minor develops and nurtures skills of observation, analysis, empathy, and self-reflection - essential for humane healthcare and helpful in understanding how culture interacts with the individual experience of illness and how healthcare is practiced and experienced. The minor also models the interdisciplinary and collaborative work that is a central feature of the University of Colorado's strategic priorities. Students must have a 2.5 overall GPA and successfully complete the required "Introduction to the Health Humanities" course, three electives, and one capstone course in a humanities discipline that incorporates substantial original writing or research projects designed to promote broad reflection on the role of culture, society and ethics in healthcare.

$\begin{array}{ll}\text { Institution: } & \text { University of Delaware } \\ \text { Program: } & \text { Medical Humanities }\end{array}$ 
Type: Minor

Location: Philosophy Department

Established: 1990

Contact: $\quad$ Mark Greene

Associate Professor of Philosophy

mkgreene@udel.edu

(302) 831-2359

Program: The minor explores how different kinds of humanistic inquiry inform and are

Description: informed by the science and practice of medicine.

Institution: University of Massachusetts Boston

Program: Science, Medicine, \& Society Past \& Present

Type: Minor

Location: History Department

Established: 2013

Contact: Olivia Weisser

Assistant Professor

olivia.weisser@umb.edu

(617) 287-6865

Program Science, Medicine, and Society: Past and Present at UMass Boston offers

Description: undergraduate students across the colleges a way of reflecting upon the traditions and historical origins of their fields of study. For instance, biology pre-meds can learn about the historical background of medicine when studying the sociology of contemporary medical practice, and students in the School of Nursing can learn about the professional and intellectual history of nursing while engaged in their practical training. Students in the School for the Environment can learn about environmental thinking not only from the time of Love Canal, but also from the time of Linnaeus and Lucretius. A transdisciplinary and historical perspective offers students a deeper understanding of their fields of study, and also gives them the tools to think about those fields more critically. History students, by contrast, can reach out from their accustomed humanities classrooms and explore how other disciplines respond to the challenges, say, of bioethics or the epidemiology of addiction. The minor requires students to take at least two survey courses, which focus on the development of trends, techniques and knowledge over two to two-and-a-half centuries. After completing this first requirement, minors will take four courses that explore in-depth developments with tighter thematic and geographic limitations. These courses are intended to allow students to pursue their research and professional interests.

Institution: University of Nebraska - Lincoln

Program: Humanities in Medicine

Type: Minor

Location: College of Arts and Sciences

Established: 2008 
Contact: $\quad$ Rose Holz

Professor and Director, Humanities in Medicine

rholz2@unl.edu

(402) 472-9392

Program UNL's Humanities in Medicine is an interdisciplinary program designed to support Description: students' learning about the social and cultural contexts of health, illness and medical care. Because health care is never carried out in isolation from the economic, social and political realities of contemporary society, the program explores health within its larger social context. The program's goal is to develop a broad understanding of the human side of health care by offering undergraduates an organized opportunity to take courses in diverse fields. The program began in 1996 with the support of a gift from Linda and Charles Wilson. The Wilson Fund provides scholarships for pre-medicine students who major in a humanities field and are pursuing the HMED minor. It also provides support for visiting speakers and special events. The interdisciplinary minor began in 2008 and has grown in popularity each year, attracting students pursuing a wide variety of majors.

Institution: University of Oklahoma

Program: Medical Humanities

Type: BA-MD, Minor

Location: Honors College

Established: 2000

Contact: $\quad$ Sarah Tracy

Director, Univ. of Oklahoma Medical Humanities Program swtracy@ou.edu

(405) 325-5291

Program The University of Oklahoma Honors College and College of Medicine offer motiDescription: vated students with interests in health, disease, and the healing professions two opportunities to study the medical humanities, broadly defined as the history, sociology, and ethics of medicine, medical anthropology, literature and medicine, bioethics, and arts as they relate to medicine. These two opportunities are individually tailored minors in the medical humanities, which students design according to their interests, and positions within a highly selective BA-MD program. Students with a 3.4 college GPA may complete a Medical Humanities Minor. Baccalaureate-MD students enter the University of Oklahoma Honors College from high school and are granted provisional acceptance at the OU College of Medicine. Five to eight Medical Humanities Scholars (BA-MD students) are admitted to this program each year. The program began in 2000. The Medical Humanities Program is designed to encourage students with health-related interests to consider the dynamic relationship between medicine and society and the ways that culture, ethics, economics, politics, and history have shaped how we understand health, disease, and their management. Students are encouraged to explore the art as well as the science of healing practices, and to gain an appreciation for the patient and healer experiences within a wide range of cultures through the study of history, literature, anthropology, sociology, bioethics, political science, music, and the visual arts. 
Institution: University of Pittsburgh

Program: Conceptual Foundations of Medicine

Type: Certificate

Location: History and Philosophy of Science Department

Established: 1975

Contact: Joann McIntyre

Departmental Secretary

vanna@pitt.edu

(412) 624-5896

Program The undergraduate program in the Conceptual Foundations of Medicine is Description: designed to offer a group of related courses in the areas of medical ethics, the nature of explanation and evidence in the biomedical sciences, and social problems such as assessments of alternative forms of health care delivery. The program is likely to be of particular interest to pre-medical and preprofessional health care students, but is intended to appeal to all students interested in social and philosophical problems in the biomedical sciences. Students interested in obtaining the the undergraduate certificate should apply as early in their course work as possible. Normally, satisfactory completion of one course in the two-term core sequence, History and Philosophy of Science (HPS) 0612-Mind and Medicine or (HPS) 0613-Morality and Medicine, is required for admission into the certificate program. Applications can be secured from the Department of History and Philosophy of Science.

Institution: University of Pittsburg

Program: Medical Humanities

Type: Certificate

Location: Center for Bioethics and Health Law

Established: 2018

Contact: Mark Paterson

Certificate Director

paterson@pitt.edu

(412) 648-7007

Program The University of Pittsburgh's Dietrich School of Arts \& Sciences is planning a

Description: new undergraduate Certificate in Medical Humanities (CMH) designed for prehealth students, as well as those interested in science writing, journalism, or critical engagement with the biomedical sciences. The Certificate involves the exploration of the experience of illness, mortality, fragility, health, and healthcare settings through literature, the arts, and the social sciences. With the goal of promoting interdisciplinary inquiry into a range of biomedical themes including the meanings, experiences, genealogy, social structures, and cultures of medicine and healthcare, the Certificate in Medical Humanities is designed to complement the University's long-standing Certificate in the Conceptual Foundations of Medicine. Departments and programs collaborating to develop and offer courses for the $\mathrm{CMH}$ include: Anthropology; Art \& Architecture; Bioethics; Classics; 
English Literature and Writing; Gender, Sexuality \& Women's Studies; History; History \& Philosophy of Science; Religious Studies; and Sociology. The Certificate's 18 credit curriculum will begin with two gateway courses - one in literature, the arts, \& medicine and another in society \& health - to introduce the interdisciplinary content and approaches of the medical humanities. Building on these, students will choose three elective courses and either a capstone seminar or directed research project. The program, open to undergraduates across the entire University, will enroll its first students in Fall 2018. For additional information contact Mark Paterson, PhD, paterson@ pitt.edu, or the Center for Bioethics \& Health Law, bioethics@pitt.edu.

$\begin{array}{ll}\text { Institution: } & \text { University of Texas-San Antonio } \\ \text { Program: } & \text { Medical Humanities } \\ \text { Type: } & \text { Major } \\ \text { Location: } & \text { Philosophy and Classics Department } \\ \text { Established: } & 2015 \\ \text { Contact: } & \text { Eve Browning } \\ & \text { Professor and Chair, Philosophy and Classics } \\ & \text { eve.browning@utsa.edu } \\ & (210) 458-5080\end{array}$

Program The Bachelor of Arts degree in Medical Humanities is an interdisciDescription: plinary degree which allows students to combine education in the humanities and social sciences with their scientific training in order to advance their career goals in the health and medical professions. Medical Humanities at UTSA offers two tracks: (1) Pre-Med: includes all required course work for Texas medical schools, plus electives drawn from humanities and social science disciplines. Allows students to personalize their pre-med major to their interests and future areas of expertise. (2) Health Careers: Includes course work in sciences, social sciences, and humanities for a broadly interdisciplinary preparation for a variety of health care career tracks. Students in Medical Humanities UTSA will have the opportunity to attain a comprehensive and forward-looking understanding of, and appreciation for, the scientific, social, ethical, and cultural dimensions of health care.

Institution: University of Texas-Dallas

Program: Medical and Scientific Humanities (MaSH)

Type: Minor

Location: School of Arts and Humanities

Established: 2001

Contact: Pamela Gossin

Professor, History of Science and Literary Studies;

Director, Medical and Scientific Humanities

psgossin@utdallas.edu

(972) 883-2071 
Program This program aims to attract students across the "two cultures" to foster Description: interdisciplinary understanding of the humanities, medicine and the sciences. MaSH provides opportunities for students across the "science-humanities" gap to take courses together that explore and experiment with ideas, discoveries, issues and concerns in medicine and the sciences. MaSH courses cover four thematic core areas: 1) Humanistic Relations of Medicine and the Sciences; 2) Ethical and Philosophical Contexts; 3) Communication and Creative Expression; and 4) Cultural and Social Contexts. Some courses emphasize the interrelations of science and medicine with the humanities through the materials, products, methods and processes of art, film, literature, history and philosophy, e.g, by exploring medical and scientific biographies and autobiographies, films or literary works that examine scientific themes and ideas (such as science fiction and nature writing), the history and philosophy of science and medicine and medical ethics. Others offer humanistic perspectives and skills especially relevant to careers in medicine and science, including: complex problem-solving and thinking; cross-cultural and professional communication; creative and compassionate approaches to interpretation and analysis; and deeper understanding of the range and diversity of human values, emotional expression and behavior. For students seeking a true "liberal arts" training or aspiring to be socially conscious and scientifically literate artists, creative writers, future STEM teachers, or business leaders, for those in-training for health careers as compassionate doctors, dentists, physician assistants, pharmacists, physical therapists or optometrists, Medical and Scientific Humanities brings together the best of both worlds for meaningful life in the twenty-first century.

$\begin{array}{ll}\text { Institution: } & \text { University of Washington } \\ \text { Program: } & \text { Bioethics } \\ \text { Type: } & \text { Minor } \\ \text { Location: } & \text { Department of Bioethics and Humanities } \\ \text { Established: } & 1997 \\ \text { Contact: } & \text { Erika Blacksher } \\ & \text { Associate Professor of Bioethics; } \\ & \text { Director of Undergraduate Studies } \\ & \text { eb2010@ uw.edu } \\ & \text { (206) } 685-9532\end{array}$

Program The Minor in Bioethics is designed for undergraduates planning careers Description: in the health sciences and health professions, such as medicine, public health, global health, nursing, social work, pharmacy, among other health-related fields. Courses address ethical issues in health care, health policy, public health, and the conduct of health sciences research; introduce students to ethical theories and methods of analysis and build capacities for critical reasoning, ethical inquiry, and team 
work; and provide students with an appreciation of the social, cultural, and political contexts that frame bioethical issues. Course formats vary from small seminars that create ample opportunity for student-student and student-instructor interaction to larger lecture-driven courses. In addition to regularly scheduled courses, students may pursue the independent research with the supervision of a $\mathrm{BH}$ faculty member (contingent on faculty member availability and interest). Courses are taught by faculty from diverse disciplinary backgrounds who are experts in their respective fields. The minor program actively seeks to attract and serve students with diverse identities and backgrounds. Established in 1997, the program is the only minor available for undergraduates in the UW School of Medicine and is one of the few that exist in the West.

$\begin{array}{ll}\text { Institution: } & \text { Virginia Commonwealth University } \\ \text { Program: } & \text { Medical Humanities } \\ \text { Type: } & \text { Minor } \\ \text { Location: } & \text { Science, Technology, and Society (STS) } \\ & \text { Program in the Department of History }\end{array}$

Established: 2013

Contact: Karen Rader

Professor of History and Director, STS Program

karader@vcu.edu

(804) 828-9642

Program The VCU Medical Humanities minor seeks to provide undergraduates who have Description: academic or professional interests in the medical sciences with an enriched curriculum which addresses the non-scientific aspects of professional health care training. The core courses from the Departments of History and Gender, Sexuality, \& Women's Studies (SCTS 301/ENGL 369, cross-listed as GSWS 391/Illness Narratives), Art History (ARTH 361/The Human Condition: An Arts Perspective) and Philosophy ((the course PHIL 213/The Ethics of Healthcare) cultivate three competencies - empathy and self-reflection, visual observation, and ethical analysis - that are essential for humane care. The elective courses, drawn from a wide variety of scholarly fields in the humanities and social sciences, illuminate the social and cultural contexts that frame understandings and experiences of health and illness. The minor further enriches pre-medical student training in areas that the MCAT MR5 deems necessary for future physicians - namely, the social and behavioral sciences - and it prepares students to think critically about race, class, and gender disparities in health and access to healthcare. At the institutional level, the minor increases faculty and student engagement by providing an interdisciplinary learning experience conceived within the framework of VCU's Quest for Distinction Strategic Plan: the minor is flexible and inquiry-driven, and it contributes an important curricular dimension to the ongoing development of VCU as an integrated research university with a commitment to human health and to addressing disparities wherever they exist. 


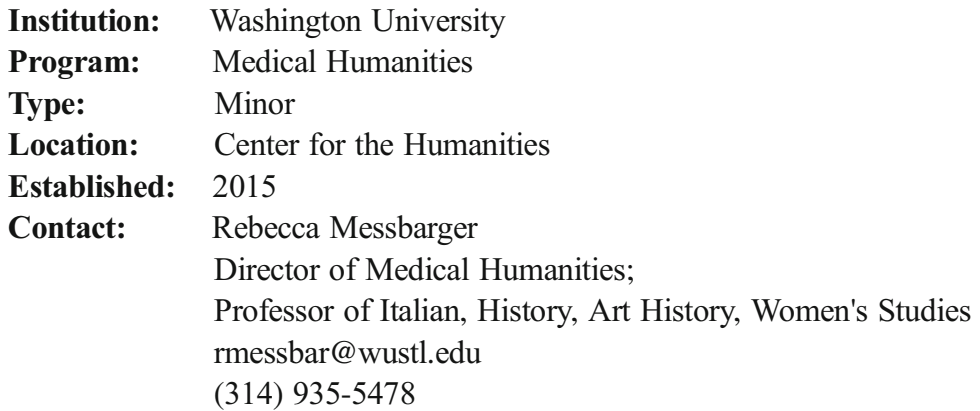

Program The Washington University Minor in Medical Humanities, whose director Description: is Professor Rebecca Messbarger, is housed in the Center for the Humanities. The minor draws on courses from across the humanities, including art history, classics, history, languages and literature, music, philosophy, and gender and sexuality studies. The minor approaches health, disease and medical care as culturally embedded human experiences that vary across time and place. In addition to exploring health, disease and medical care as core human experiences, the program of study is designed to provide a solid grounding in the textual-historical approach essential to all humanities scholarship. The minor combines disciplinary diversity with thematic unity to engage students with a set of tightly related "big" topics and issues. These include the contested meanings of health and disease; the ethical dimensions of medicine; illness narratives; the role of medicine in war, empire and nation building; the relationship between religion and medicine; the relationship between biomedicine and other healing traditions; and the burden of disease as it relates to gender, race and class. Medical Humanities aspires to instill values shared by all humanities disciplines: to appreciate multiple worlds and viewpoints, to communicate eloquently, and to read and think critically. Students will emerge from the minor able to apply the insights and critical methods of literature, philosophy, history and the arts to subjects often left solely to the natural and social sciences. Its goal is to demonstrate the enduring relevance of humanistic inquiry to understanding a basic realm of human experience.

$\begin{array}{ll}\text { Institution: } & \text { West Virginia University } \\ \text { Program: } & \text { Medical Humanities and Health Studies } \\ \text { Type: } & \text { Minor } \\ \text { Location: } & \text { English Department } \\ \text { Established: } & \text { Under Review } \\ \text { Contact: } & \text { Catherine Gouge } \\ & \text { Associate Professor of English } \\ & \text { cgouge@ @vu.edu } \\ & \text { (304) 293-3107 }\end{array}$


Program: The undergraduate minor in "Medical Humanities and Health Studies" at West Description: Virginia University aims to provide students with an understanding of the social and cultural contexts of health, illness, and medical care and to give students a broad understanding of how the perspectives of the humanities and social sciences can help us think productively beyond an idea of health and medicine as pure science. The program will consist of courses taught by faculty from Communication Studies, Disability Studies, English, Geography, Gerontology, Philosophy, Political Science, Psychology, Social Work, Sociology and Anthropology, and Women's and Gender Studies. By encouraging interdisciplinary study, the program will help students learn to identify and differentiate among different humanities and social science perspectives on health and medicine; to analyze a variety of cultural products of health and medicine, using the analytical methods of three or more disciplines; to employ the research tools and composition skills appropriate to scholarship in three or more disciplines; and to explain in written and spoken form the significance of humanities and social science perspectives on health and medicine. In so doing, the minor will promote an awareness of the shared interests and connections among multiple disciplines in the study of health and medicine. In addition to serving students whose major area of study intersects with issues related to health and medicine, the minor will benefit students seeking to do graduate work in related fields as well as those seeking employment in the health professions directly following completion of their undergraduate degree programs.

\author{
Institution: Western Michigan University \\ Program: Medical Humanities \\ Type: Minor \\ Location: Various Departments (Interdisciplinary) \\ Established: 2013 \\ Contact: $\quad$ Fritz Allhoff \\ Professor \\ fritz.allhoff@wmich.edu \\ (269) $387-4503$
}

Program The medical humanities minor is beneficial for two kinds of students who wish to

Description: understand the humanistic elements of health and health care, including the psychosocial, ethical, religious, literary, artistic, and so forth. Those choosing a career in the health sciences will find medical humanities to be a positive influence on how they approach patient care, helping them to view patients with greater empathy and awareness of what it is to be a patient. Meanwhile, students of traditional disciplines within the humanities will encounter and explore the human condition as it relates to health-related adversity and triumph. 